\title{
Território das Instituições Federais de Ensino Superior Brasileiras (IFES): uma reflexão sobre o planejamento de campus e suas práticas na década de 70 e atual
}

\author{
ALMEIDA, Jaime G. de ${ }^{1}$ \\ 1 Departamento de Projeto, Expressão e Representação de Arquitetura, Faculdade de Arquitetura e Urbanismo, \\ Universidade de Brasília, Brasília, Brasil. E-mail: cantoar@unb.br
}

\begin{abstract}
Resumo
discute o processo planejamento de campi universitários das IFES tendo em vista suas práticas e fundamentações. A análise é comparativa abrangendo dois momentos históricos, a saber: o planejamento da década de 70 , sob os governos militares, e o planejamento da década de 80, destacando o período posterior à redemocratização do país. Discorre sobre o significado de cidade universitária e campus, entre outros termos utilizados na análise. Evidencia a crise do planejamento e aponta como prováveis causas a falta de um sistema nacional de planejamento de território universitário e o impasse de seus fundamentos, a exemplo do estruturalismo dos anos 70 e pragmatismo de agora.
\end{abstract}

Palavras-Chave: Processo; MEC; Ciclo Básico; Crise; Estruturalismo; Pragmatismo.

\begin{abstract}
it is discussed the process of the Brazilian university campus planning focusing at its practices and theories. The analysis is comparative and considers two main historical periods prescribed: the years of 70 , under military governments and the years of 80 , especially the period of postdemocratization of Brazil when the universities became mass institutions. The main concepts related to the university organizations and their territories are analyzed. May be the crises of university spatial planning is due to loss of the national planning system and also to problems in its theoretical background, as for example, the structuralism in seventies and pragmatism in eighties.
\end{abstract}

Key-Words: Process; MEC; Basic Cycle; Crisis; Structuralism; Pragmatism. 


\section{Introdução}

Aliás, aprendi que o planejamento deveria ser estratégico, e não exaustivo, deveria ser contínuo e flexível, capaz de ajustar paulatinamente seus objetivos, tomando a cada vez, o mínimo de decisões necessárias para se manter na trajetória desejada.

Agnacy Sachs

A história recente da ocupação do território das IFES nos coloca várias questões acerca da crise de seu planejamento físico-espacial provavelmente agravada pelos programas e decisões políticas do governo federal via MEC.

Neste trabalho, entretanto, serão analisadas duas questões. A primeira se refere à decisão políticoadministrativa do MEC em abolir o sistema existente que coordenava em nível nacional o planejamento físico-espacial das IFES. Decisão essa ocorrida no período da redemocratização do país a partir de 1985.

A segunda compreende a supressão do ciclo básico pelas IFES. O básico tinha dupla finalidade, uma voltada aos estudos propedêuticos, iniciais e obrigatórios dos calouros de graduação e, a outra, de integração de unidades universitárias por área de conhecimento.

A supressão do ciclo básico concorreu decisivamente para o agravamento da crise do planejamento do território universitário. Haja vista que práticas desse planejamento durante os anos 70 se voltaram para a concretização da universidade integrada (universidade orgânica) e do ciclo básico. Esta instituição acadêmica contribuiu decisivamente para a renovação do urbanismo e da arquitetura do campus. $\mathrm{O}$ exemplo mais significativo desse fato consiste na proposição de edifícios extensos fisicamente destinados às funções múltiplas e interdisciplinares.

Dos anos 80 adiante, sem contar com o apoio de um sistema nacional de planejamento as IFES optaram por uma prática de planejamento do "aqui e do agora”. E, no lugar de uma com visão mais abrangente que o estruturalismo lhes propiciava adotaram o seu oposto o pragmatismo.

Veremos na primeira parte deste trabalho o significado destes dois termos além dos termos campus e cidade universitária. Aliás, verifica-se uma confusão entre eles em documentos do MEC e Conselho Federal de Educação (CFE).

A partir do final dos anos 80, o planejamento das IFES ficou praticamente sem nenhum mecanismo de articulação entre elas e delas com instituições federais a exemplo do MEC. Provavelmente em decorrência dessa situação, as IFES escolheram um processo de projeto voltado às unidades prediais exclusivas, ou melhor, edificações monofuncionais.

Há outras implicações decorrentes dessa opção no processo de planejamento físico-espacial, quais sejam: em primeiro lugar, a preeminência de decisões político-administrativas em que sobressaem os interesses exclusivos das unidades universitárias em detrimento do todo; e, em segundo lugar, a preferência por soluções pontuais cujo foco é centrado em projetos de edificações deixando o planejamento do território universitário de "escanteio".

Este trabalho objetiva, portanto, discutir o planejamento físico das IFES visando compreender seus horizontes e suas práticas. $\mathrm{Na}$ análise, será considerado, por um lado, o planejamento dos anos 70 , sob os governos militares e, por outro lado, a situação do planejamento após a redemocratização do país nos anos 80. Depreende-se da comparação desses dois momentos uma mudança significativa nos rumos do planejamento do território universitário.

Ao longo do texto, recorrerei a minha experiência com o planejamento universitário dos anos 70 a 90 . Por exemplo, no MEC de 1975-1980, desempenhei a função de arquiteto no Programa de Melhoria das Instalações do Ensino Superior, Departamento de Assuntos Universitários, Ministério da Educação (PREMESU-DAU/MEC). Este órgão, entre 1974 até 1980, coordenou a implantação de campi das universidades federais brasileiras. Administrou também os principais programas de investimentos financeiros na infraestrutura física das IFES (construções de edifícios, compra de equipamentos e mobiliário) além de ações específicas voltadas à capacitação de seus docentes.

Nos anos 70, os governos militares reorientaram a política de implantação de campi universitários 
promovendo, entre outras medidas, as seguintes: criação de um órgão com função de coordenação de programas voltados aos campi, centralizado no governo federal (MEC); universalização do modelo de campus universitário organizado em torno do ciclo básico; e, correlacionado com essas ações, implantação das IFES em terrenos extensos e localizados na periferia das cidades.

O MEC condicionou, porém, os seus investimentos no campus à venda dos imóveis pertencentes às IFES situados nas áreas urbanas. Assim, os recursos financeiros arrecadados com essa venda teriam de ser investidos no campus.

Tocou ao PREMESU a execução dessa política. Mas esse órgão com pouco tempo de existência foi transformado de programa para coordenadoria e, mais tarde, no início dos anos 80 , substituído pelo Centro de Desenvolvimento e Apoio Técnico (CEDATE) que acabou sendo extinto pouco tempo depois da sua criação.

Ao contrário do PREMESU, o CEDATE se dedicou quase que exclusivamente à realização de estudos e promoção de encontros sem se envolver diretamente com o planejamento territorial das IFES. Contudo, a eliminação dessas duas instituições, as questões relativas ao planejamento físico-espacial das IFES ficaram sem representação no MEC, isto é, no governo federal em Brasília.

Desde então, as IFES passaram a cuidar por elas mesmas de seu planejamento físico-espacial. As possíveis ações conjuntas entre elas, que de alguma forma aqueles órgãos lhes propiciavam, não tiveram prosseguimento.

Acontece que a infraestrutura física das universidades e a gestão de seus órgãos técnicos (escritório, departamento de planejamento, prefeitura, etc.) passaram a sofrer pressões da população acadêmica por instalações físicas. Provavelmente os programas federais de fomento entre outras ações do MEC contribuíram para o agravamento desse fato. É o caso do Programa de Apoio aos Planos de Reestruturação e Expansão das Universidades Federais (REUNI), instituído pelo Decreto Presidencial no 6.096 de 24/4/2007.

Em decorrência dessas medidas, a ideia do campus plasmada na universidade orgânica foi substituída por um arranjo institucional em que se evidenciam as unidades universitárias per se (faculdades, institutos, unidades complementares, etc.). Por outro lado, o planejamento enquanto processo fomentador de experiências metodológicas e da industrialização da construção no campus cedeu lugar inicialmente para os planos diretores e, depois, para uma modalidade indireta de controle de projetos para o campus por meio de diretrizes e requerimentos gerais.

Este trabalho está organizado em três partes: (1) discute o significado de cidade universitária, campus, estruturalismo e pragmatismo; (2) apresenta um resumo das práticas de planejamento do território universitário concernente ao período anterior e posterior a redemocratização do país; (3) analisa os dilemas do planejamento das IFES; e, finalmente, (4) as conclusões.

Significado de cidade universitária, campus, estruturalismo e pragmatismo.

Desde a criação das primeiras universidades brasileiras entre as décadas de 20 e 30 e até os anos 60 três modelos de organização físico-espacial podem ser identificados, quais sejam: o de unidades dispersas na cidade (etapa inicial), o da cidade universitária (etapa intermediária) e do campus (etapa atual).

A rigor, a primeira etapa de configuração espacial da universidade brasileira não é um tipo exclusivo. Trata-se de um sistema proforma de universidade constituída por faculdades e institutos superiores de ensino, a exemplo da Faculdade de Direito, Engenharia, Medicina e do Instituto de Educação. Essas escolas se agrupavam em determinadas praças urbanas, conhecidas como praça universitária, ou em certas áreas urbanas denominadas de bairro universitário. Essa modalidade de universidade teve início na república velha 1889-1930.

Agora a constituição da maioria das cidades universitárias aconteceu na república nova a partir de 1930 ou um pouco antes. Eram universidades melhores organizadas, porém, autárquicas. Um de seus projetos representativos é o da Universidade Federal do Rio de Janeiro (UFRJ) de 1937 para um terreno na Quinta da Boa Vista, Rio de Janeiro. Seu plano diretor é modernista de autoria do arquiteto 
Lúcio Costa e equipe e colaboração do arquiteto Le Corbusier.

Porém, no início da década de 50, o plano da UFRJ, elaborado pelo arquiteto Jorge Moreira e equipe, foi implantada na Ilha do Fundão, nessa mesma cidade. A organização dessa universidade (ver FÁVERO, 2000) e, sobretudo, do seu plano urbanístico representam um dos exemplares paradigmático de cidade universitária de grandes dimensões. Caracteriza-se pelo agrupamento em um só terreno de instituições autárquicas (faculdades de direito, engenharia, medicina, etc.) sob a coordenação de uma administração central, a reitoria e seus órgãos colegiados.

Entretanto, o campus é uma concepção de espaço e organização acadêmica, administrativa oposta à da cidade universitária. O campus foi implantado no país sob a provável influência do planejamento físico da Universidade de Concepción Del Chile. O campus dessa universidade possui características de cidade-jardim ou cidade-parque. Foi projetado em 1957-8 pelo arquiteto chileno Emilio Duhart Harostegui que se inspirou no campus da Universidade de Berkeley, Califórnia - Estados Unidos. É um plano diretor organizado por três elementos principais, quais sejam: zoneamento de áreas exclusivas; lugar central, onde estão localizados o Foro Aberto (anfiteatro) e Campanário; e, as ruas estruturais convergindo para o centro.

No entanto, observa Saavadra (2009) que o planejamento de Harostegui foi motivado pelo primeiro reitor dessa universidade Enrique Colina que era um entusiasta do campus daquela universidade americana. A autora observa ainda que Atcon, consultor da UNESCO, colaborou na organização dessa universidade em 1957, indicando-lhe, entre outras proposições, o desenvolvimento de pesquisa científica e a implantação de institutos centrais em lugar de faculdades.

No Brasil, um dos campi pioneiros é sem dúvidas o da Universidade de Brasília (UnB), conforme o projeto de Darcy Ribeiro $(1961,1960)$ que contou entre outras contribuições com a de Heron de Alencar (ALENCAR, 1978). Esse plano foi elaborado no começo da década de 60 sendo a construção do campus iniciada em 1962 concomitantemente com a implantação de seus cursos troncos.

O planejamento da UnB previa um modelo integrado de atividades em que se destacavam os seguintes elementos-chave: ciclo básico (ver SUCUPIRA, 1970); colegiados e congregações (carreira, básico, etc.); institutos centrais; departamento como a menor unidade do sistema; fundação mantenedora; sistema de crédito; administração central; e, com relação às edificações, o critério da flexibilidade de uso, padronização construtiva, entre outros.

Porém, a introdução no Brasil da ideia do campus, do ciclo básico e dos institutos centrais é atribuída a Rudolf Atcon (1970, 1974), quando ele aqui esteve assessorando o MEC e o Conselho de Reitores das Universidades Brasileiras (CRUB). Atcon, segundo Fávero (1991), atuou em outras ações relacionadas com a universidade brasileira. Porém, a partir de 1968, o governo militar tornou a UnB e seu campus modelos nacionais por meio da Lei de Diretrizes e Bases da Educação (LDB) no 5.540 de 28/11/1968.

A escolha da UnB como modelo a ser repetido por outras universidades federais com realidades diferentes coloca-nos a questão da mudança de uma utopia para uma ideologia (ver BOSI, 2010, e, KONDER, 2002), o que significa a imposição de uma certeza. Possivelmente essa decisão tomou corpo quando a maioria dos professores da UnB, em 1965, pediu demissão em protesto contra a interferência dos militares na universidade (ver SALMERON, 1999).

O ciclo básico da UnB lembrava em muitos aspectos os "Colleges" ingleses (ver RASHDALL, 1945) e norte-americanos. Há, porém, uma diferença marcante entre o nosso básico e o das universidades americanas e inglesas. Este se concentrava na educação humanista do calouro enquanto que aquele nas disciplinas fundamentais das áreas de conhecimento (básico de artes, ciências biológicas, exatas e humanas). Por exemplo, as ciências exatas (engenharias, geologia, etc.) compartilhavam disciplinas como, por exemplo, matemática e química, já as ciências humanas e sociais (letras, filosofia, sociologia, etc.), estatística e metodologia científica. Mas havia um conjunto de 
disciplinas obrigatórias a todos as áreas como o ensino da língua portuguesa e de uma estrangeira.

O campus da UnB inovou em muitos aspectos o planejamento do território e a arquitetura das IFES. Por exemplo, seu primeiro plano diretor é de autoria do arquiteto Lúcio Costa (ver UNIVERSIDADE DE BRASÍLIA, 1962). No entanto, este plano era organizado por edificações independentes, mas articuladas pelo sistema viário e equipamentos de uso comum. Em 1962, o arquiteto Alcides da Rocha Miranda e equipe optaram por um sistema de unidades integradas que foi consolidado na Faculdade de Educação (FE/UnB).

Em seguida, o arquiteto Oscar Niemeyer e equipe retrabalhou o plano diretor do campus aproximando-o da proposta de Darcy Ribeiro. Esse plano diverge do plano de Lúcio Costa, pois é estruturado por um grande edifício multifuncional e interdisciplinar, situado no centro do campus. Sua estrutura é composta por dois pórticos préfabricados que se repetem ao longo de uma circulação (rua interna central ajardinada, longitudinal e encurvada) com aproximadamente $700 \mathrm{~m}$ de comprimento. Foi denominado de Instituto Central de Ciências (ICC) e apelidado de Minhocão. Nele, foram alojados os institutos de ciências, unidades básicas que asseguravam a existência da universidade orgânica. Afora esta característica, havia, por exemplo, o compartilhamento de seus ambientes por diferentes unidades acadêmicas além da flexibilidade interna seguindo às mudanças de uso.

Depois da experiência da UnB, já nos anos 70, a Universidade Federal de Minas Gerais (UFMG) inaugurou um processo diferenciado de planejamento do seu campus a partir do ciclo básico. Essa universidade desenvolveu ainda a ideia urbana de campus, isto é, um campus adensado construtivamente procurando incentivar o compartilhamento social dos espaços. A proposição inicial desse sistema é de 1973 e sua autoria do arquiteto Abílio Castelo Branco e equipe. Em seguida, outra equipe mineira deu continuidade a essa proposta fundamentada no estruturalismo enquanto método e teoria de planejamento e projeto (MALARD, 2012).
À semelhança da UnB, as edificações e o planejamento do campus da UFMG pressupunham a ideia de unificação da ciência e a proposição de espaços universais e flexíveis às mudanças na organização universitária e nos processos de ensino e pesquisa (CASTELO BRANCO, 2012).

A arquitetura inovadora do ciclo básico da UFMG compreende um módulo estrutural quadrangular quase cúbico que adicionado uns aos outros resultam em uma malha geométrica ortogonal indiferenciada. É concepção arquitetônica próxima da "built-form" do tipo cruciforme do grupo de Cambridge (veremos mais adiante) e, de acordo com Maciel (2011), com a malha estrutural, projetada em 1963, pelo arquiteto grego Georges Candilis e equipe para a Universidade Livre de Berlim.

Nessa mesma década, estavam em curso outras modalidades de planejamento de espaço universitário calcadas no modelo de campus, mas produzindo soluções arquitetônicas e urbanísticas divergentes da experiência da UFMG e UnB. São, por exemplo, a opção da Universidade Federal do Espírito Santo (UFES) pelo modelo de edificação fechada em si denominada de CEMUNI. Essa edificação, projetada em dois pisos, foi reproduzida no campus, daí o nome célula universitária. Sua característica arquitetônica principal é o pátio interno e descoberto circundado pelos ambientes construídos.

A Fundação Universidade Federal do Amazonas (FUAM), do Rio Grande do Sul (UFRS) e de Sergipe (UFSe) escolheram o sistema de edifícios composto por pavilhões articulados. Essa morfologia arquitetônica é talvez a mais representativa das universidades brasileiras. Trata-se de um tipo arquitetônico bastante utilizado pelo modernismo que perdura até hoje nas IFES.

Com relação aos dois termos mencionados, o estruturalismo em arquitetura refere-se à estrutura predial e, ao mesmo tempo, à ideia sistema (conjunto de relações funcionais entre um número definido de elementos) almejando a universalidade e abstração. É um método de resolução de problemas que leva em conta as relações entre elementos (atividades e espaços) considerando as semelhanças ou oposições entre eles (sintaxe). 
Emprega a técnica de subdivisão sistemática dos grupos de atividades em pequenos agrupamentos até alcançar a unidade indivisível. Sua principal variável é a função, daí podermos concluir que se trata de uma teoria funcionalista. Mas, esse processo de planejamento desconsidera a história e seus conteúdos expressivos (semântica).

No universo do planejamento do campus no Brasil, o estruturalismo introduziu a modelação matemática, o emprego de recursos estatísticos e conceitos como os de metaplanejamento e metaprojeto. Antecipou o uso da automação computacional no trato das informações provenientes de atividades e, sobretudo, nas prospecções sobre o futuro do território universitário. Esta teoria muito contribuiu para a renovação dos métodos de planejamento do campus universitário especialmente as de projeto de arquitetura do ciclo básico. Diferentemente dos ingleses, os nossos estruturalistas não desenvolveram estudos empíricos sobre o uso e a apropriação de espaços, limitaram-se, porém, às proposições teóricas (ver UFMG, 1970).

Já o pragmatismo é, contudo, uma opção metodológica de resolução de problemas de ordem prática, isto é, de dificuldades delimitadas e concretas. Valoriza a experiência e utilidade e evita sobremaneira questões globalizantes, universais e abstratas como acontece com o estruturalismo. Concentra-se, porém, na ação direta e, em decorrência disto, analisa os problemas per se, levando em conta suas próprias variáveis e, sobretudo, o seu contexto imediato.

\section{Práticas de Planejamento de Campi Universitários nos Anos 70}

As atividades governamentais de planejamento de campi tiveram início no Decreto no 63.341 de 1/10/1968 e Decreto no 60.461 de 13/3/1967 que instituiu no MEC a Comissão Especial para Execução do Plano de Melhoramento e Expansão do Ensino Superior (CEPES). Esta comissão coordenou os primeiros investimentos financeiros do governo federal nos campi das IFES.

Entretanto, a CEPES foi logo substituída pelo PREMESU-DAU/MEC, órgão criado pelo Decreto no 73.857 de 14/3/1974. De fato, o nome PREMESU se tornou nova denominação da CEPES a partir desse decreto. Mais tarde, o PREMESU foi sucedido pelo Centro de Desenvolvimento e Apoio Técnico (CEDATE) sendo este extinto pela Lei no. 7.731 de 14/2/1989. Desse modo, a coordenação e a articulação do planejamento físico-espacial das IFES pelo MEC perdurou vinte e dois anos, e grande parte desse tempo sob os governos militares.

A modalidade de planejamento desses órgãos notadamente do PREMESU teve seu apogeu nos anos 70. Nesse período, ocorreram os principais financiamentos internos e externos promovidos pelos governos militares para a consolidação da infraestrutura física das IFES.

Com relação aos projetos das edificações no campus, o PREMESU atuava em duas frentes de trabalho, uma geral que compreendia a análise das fundamentações acadêmico-institucional dos planos de obra e, outra específica, a avaliação de projetos especialmente os de arquitetura que estavam contemplados nos recursos provenientes de financiamentos.

Assim, o plano diretor do campus fazia parte da análise de projetos de arquitetura e engenharia, dado a importância do quesito localização das edificações programadas. Porém, a elaboração de planos diretores sob a coordenação do PREMESU era esporádica. Um dos planos elaborado integralmente foi o da Universidade Federal do Sergipe (UFSe), no município de São Cristovão, pela equipe técnica da Universidade de São Paulo (USP - Butantã).

Havia no PREMESU uma comissão de consultores externos responsáveis pela a avaliação de projetos de arquitetura. Essa comissão era composta, por exemplo, por administradores, arquitetos (principalmente professores universitários) e engenheiros. A escolha desses consultores tinha como critério principal sua experiência técnicoprofissional especializada. Os técnicos do PREMESU não participavam do exame, limitavamse, porém, ao assessoramento dos trabalhos da comissão. Os temas analisados eram diversificados como, por exemplo, fundamentação, programa acadêmico e de necessidades de projetos como, por exemplo, de reitorias, biotérios, centros olímpicos, laboratórios e restaurantes. 
O PREMESU instituiu procedimentos para a análise das demandas físicas que previa a análise de informações acadêmicas, administrativas da universidade bem como a potencialidade socioeconômica da região (município e estado) onde ela estava inserida.

Quanto a análise de projetos de arquitetura de edificações, havia a Sistemática Geral para Acompanhamento e Avaliação de Projetos (SGAAP). O fluxo de projeto ocorria da seguinte forma: em si tratando de financiamento interno ou externo de construções por algum banco nacional ou internacional, o andamento administrativo e técnico de projetos de edificações (arquitetura e engenharia) principiava no ETA e, deste, seguia para o PREMESU. Neste, os projetos eram examinados pela comissão de especialistas e seguiam para a liberação de recursos, por exemplo, pela Caixa Econômica Federal (CEF) ou representação no Brasil do Banco Interamericano de Desenvolvimento (BID). Os técnicos do BID reexaminavam o projeto e emitiam um parecer técnico para liberação de recursos financeiros.

O PREMESU possuía outros mecanismos de trabalho para apoiar a avaliação de projetos de arquitetura a exemplo do banco de informações sobre as IFES e seus campi. Além disto, ele realizava regularmente encontros para avaliação de diversas questões referente ao planejamento físico e aos programas de construção em curso.

Entretanto, o DAU promovia outras ações de natureza técnica a exemplo do NAT (Núcleo de Assistência Técnica), que era um mecanismo federal destinado ao intercambio técnico entre as IFES, sendo liderado pelas universidades de maior capacidade técnica em planejamento de campus e elaboração de projetos de arquitetura e engenharia.

$\mathrm{Na}$ esfera nacional, as decisões relativas aos investimentos do governo federal em obras e outras ações nas IFES eram centralizadas no DAU/DAU, por meio do PREMESU e, no âmbito das universidades, na reitoria, ficando a sua execução a cargo do Escritório Técnico-Administrativo (ETA).

O modus operandi desse sistema de decisões como um todo possuía um viés técnico e financeiro apoiado em uma estrutura hierárquica e centralizado no MEC. As decisões cabiam aos estamentos administrativos e técnicos. E, por fazer parte de uma estrutura autoritária de governo, esse sistema a refletia nas suas práticas.

O pessoal do ETA elaborava termos de referência (justificativa das demandas), denominados de plano de desenvolvimento acadêmico e institucional ${ }^{1}$, projetos de arquitetura e engenharia, organizava licitações e fiscalizava obras como, também, prestava contas ao PREMESU. Alguns projetos, por exemplo, os de reitoria e biblioteca, eram realizados por empresas ou profissionais de outras IFES contratadas por meio de licitação ou de convênios respectivamente.

O corpo técnico das IFES compartilhava informações, teorias, procedimentos e práticas de planejamento e projeto correntes nos anos 70. Para termos uma visão panorâmica desse universo, comentaremos a seguir as opções existentes neste período, entretanto, por falta de espaço nos limitaremos às três principais.

A primeira modalidade trabalhava principalmente com o uso de ambientes construídos na universidade e almejava alcançar sua utilização máxima. Esses estudos foram desenvolvidos na Inglaterra pelo professor arquiteto John Musgrove da University College of London (UCL), Reino Unido. Seu grupo de pesquisa desenhou uma técnica de planejamento voltada à administração de tempos e espaços, isto é, utilização plena de ambientes universitários (salas de aula e administrativas, gabinetes de professores, laboratórios, etc.). Essa metodologia foi incentivada pelo PREMESU quando o professor Musgrove este no MEC, em Brasília, mas não alcançou a divulgação esperada entre as IFES.

A segunda modalidade enfatizava a programação e metodologia de elaboração de projetos de arquitetura e de planejamento de campus.

\footnotetext{
${ }^{1} \mathrm{O}$ plano apresentava as demandas da universidade (em termos de área a ser construída) e sua justificativa continha basicamente o seguinte: histórico da instituição; potencialidade socioeconômica da região; estrutura funcional e organizacional; políticas e diretrizes institucionais; aspectos acadêmicos e administrativos; dados sobre os cursos, alunos, professores e técnico-administrativos, custo/curso, custo/aluno; relação aluno/professor, aluno/área física, aluno/funcionário, entre outras informações.
} 
Utilizava-se no cálculo de áreas parâmetros europeus, as chamadas curvas de $D^{2} \mathrm{ft}^{2}$, que mediante procedimentos técnicos, por exemplo, o indicativo Estudante Tempo Integral (ETI) calculava-se a área (metros quadrados) parcial e total da instituição universitária. Essa opção metodológica alcançou no país grande aceitação sendo aplicada com sucesso no planejamento e nos projetos de arquitetura de unidades acadêmicas da Universidade Federal de Pernambuco (UFPe) e do Espírito Santo (UFES).

E, a terceira modalidade foi aquela que contribuiu de forma significativa para a inovação dos processos de elaboração de projeto de edificações e de planejamento do campus. Uma das ferramentas utilizada por esses arquitetos era o modelo construído por ferramentas digitais no caso da tecnologia da informação (TI). Subtende-se por modelo uma descrição matemática de um dado fenômeno real.

Esta opção metodológica dispunha de duas variantes. A primeira seguia as ideias de Christopher Alexander quanto ao método de projetos e planejamento. A Universidade Federal de Minas Gerais (UFMG) liderou essa iniciativa especialmente no projeto do ciclo básico do Campus da Pampulha, em Belo Horizonte. É nessa universidade que vamos encontrar também alguns indícios da segunda manifestação. Ela decorre dos trabalhos de um grupo de pesquisadores coordenado pelo arquiteto Leslie Martins. Esse grupo pertencia ao Center for Land Use and Built Form Studies (LUBFS) da Universidade de Cambridge (Reino Unido), cuja atuação ocorreu nos anos 60 .

O LUFPS realizou uma série de estudos empíricos acerca do uso de ambientes universitários pela população acadêmica. Suas duas principais variáveis eram a localização das edificações no campus e os deslocamentos ao longo do tempo dos estudantes.

\footnotetext{
2 Curvas de Delft é um conjunto de gráficos na forma de curva ascendente tendo no eixo horizontal valores numéricos de metragem quadrada e, no eixo vertical, número de estudantes. Havia um gráfico por curso universitário, por exemplo, para o curso de administração, arquitetura, ciências biológicas, economia, entre outros. Essas curvas foram desenvolvidas pela Universidade de Tecnologia de Delft (TU), na Holanda. Seus valores eram muito elevados, daí a necessidade de adaptá-los a realidade brasileira reduzindo-os significadamente.
}

Para isto contava com um modelo teórico de atividades, usos e edificações. Outra contribuição significativa desse grupo de pesquisa consistia no estudo das relações entre área construída e ocupação do terreno (lote urbano ou quarteirão). Assim, o grupo formulou o conceito de built-form (forma construída) e, com ele, estabeleceu comparações entre formas geométricas diversas embora com volumes semelhantes e propuseram alguns teoremas sobre o desenho das cidades vislumbrando edificações baixas e taxas mais adequadas de uso da terra.

Esperava-se que a extinção do PREMESU e do CEDATE $^{3}$, o MEC reavaliasse esse acervo de experiências e inaugurasse uma nova etapa do processo de planejamento nacional do território e infraestrutura física das IFES. Entretanto, a eliminação desses órgãos deixou o MEC sem um mecanismo eficaz que o auxiliasse no planejamento e na avaliação de suas ações nos territórios das universidades.

Na ausência de um processo nacional e local de planejamento, quais os critérios que o MEC utiliza para deliberar a respeito da destinação de recursos federais para construções e outras benfeitorias físicas das IFES?

\section{Crise do Planejamento Físico- Espacial das IFES}

Acontece, porém, que o processo de planejamento dos anos 70 começou a enfrentar problemas quando o princípio da universidade integrada foi posto inicialmente em questão com a eliminação do ciclo básico. Outros problemas concorreram para o agravamento desse quadro de dificuldades como, por exemplo, a massificação da universidade e a individuação de suas unidades, a qual gerou uma disputa acirrada entre elas por espaço. Esperava-se, contudo, que o planejamento do campus adotasse novos princípios e mecanismos exigidos pela democracia reinstalada no país especialmente o processo participativo.

As metas do REUNI de 2007 concorreram para agravar essa situação. Por exemplo, esse programa

\footnotetext{
${ }^{3}$ O CEDATE realizou estudos sobre o território universitário no Brasil, promoveu eventos para sua avaliação e publicou livros sobre essa temática incluindo um sobre o uso de taipa em escola rural.
} 
federal elevou a relação aluno/professor, o número de docente e técnico-administrativo e o tempo de permanência do aluno na universidade além de atualizar as grades curriculares. No entanto, o REUNI não promoveu a reavaliação do campus como um todo nem tão pouco do seu planejamento no sentido de avaliar antecipadamente o impacto dessas medidas em termos espaciais, funcionais e institucionais. O que se viu foi o surgimento de uma pressão enorme por área construída ou reformada no campus, sobretudo, por uma arquitetura exclusiva sem contar com um processo de planejamento articulado.

Em suma, essas mudanças colocaram em cheque o sistema planejamento até então praticado pelas IFES e, sobretudo, a ideia de campus integrado como assinala Almeida (1983 e 1988). O pragmatismo foi, então, uma decorrência desse contexto dado que não havia institucionalmente nenhum esforço voltado ao planejamento de território universitário que conduzisse essa mudança. Por outro lado, o processo de planejamento foi reduzido aos planos diretores trabalhados exclusivamente por técnicoadministrativos das universidades.

E, quanto ao relacionamento do MEC com as IFES, esse ministério adotou o procedimento do caso a caso (o salve-se quem puder) e o lançamento de editais públicos.

Em termos de arquitetura, essa modalidade de gestão territorial propiciou o surgimento no campus de uma opção estética expressionista em lugar da espartana e brutalista dos edifícios projetados pelos arquitetos e engenheiros das décadas de 60 e 70 . Exemplares dessas edificações podem ser ainda encontrados, por exemplo, no antigo ciclo básico da UFES e UFMG e, também, nos edifícios pioneiros da UnB.

Mas há duas questões de fundo na crise do planejamento físico-espacial do campus das IFES. Uma se refere aos fundamentos desse processo, o estruturalismo de ontem e pragmatismo de hoje, que necessitam ser avaliados tendo em vista sua insuficiência para o enfrentamento das questões atuais. E, a outra, a falta de novos conhecimentos originários de pesquisas, estudos comparativos, entre outros, sobre a instituição universitária e seus espaços.

\section{Conclusões}

Vimos que, na transição dos governos militares para a redemocratização do país, o sistema nacional de planejamento de campi das universidades públicas até então praticado pelo MEC foi suprimido e suas informações e experiências principalmente as que não foram publicadas se esvaneceram e, consequentemente, esse sistema não foi avaliado devidamente.

Esperava-se, por outro lado, que o MEC e as IFES o substituíssem por um processo de planejamento que tivesse sinergia com a restauração da democracia no país. Mas, o MEC resolveu simplesmente transferir para as universidades a responsabilidade de gerir por si próprias o seu planejamento físico sem contar com o apoio de um órgão de coordenação nacional. $\mathrm{Na}$ ausência deste, as relações entre o MEC e as IFES se tornaram problematizadas.

Será que uma democracia não necessita de um sistema e processo de planejamento nacional voltado a um tema tão importante como o da infraestrutura física de suas universidades públicas como um todo?

Será que o conjunto das IFES não necessite de uma instituição no MEC que trabalhe na esfera federal com as suas demandas físicas?

Pois bem, na ausência desse órgão de articulação nacional e, sobretudo, voltado ao planejamento físico, cada IFES tem enfrentado per se uma pressão cada vez maior por espaço decorrente dos agentes universitários (alunos, professores e técnicoadministrativos) como, também, das unidades universitárias, dos serviços de apoio (permissionários como instituições bancários, sindicais, etc.).

No entanto, as IFES insistem na opção pontual, isto é, nos programas de obras individualizados sem inseri-los no contexto maior, o da universidade e do campus. Cada universidade é, portanto, responsável pela formulação de sua própria demanda de espaços e de pessoas (professores e técnico-administrativos). Ao que parece, grande parte delas não dispõe de procedimentos técnicos para essa tarefa. O produto final dessas ações se limita a uma listagem de prédios a ser executada, 
em suma, uma demanda apropriada a escritórios ou empresas de arquitetura e engenharia e comissão de licitação e não a um processo de planejamento.

Ao longo do texto, foi ressaltado o fato dessas intervenções terem ao longo do tempo produzido no campus uma situação inusitada: a multiplicidade de instituições e de estruturas espaciais autossuficientes sem conexões funcionais e, por vezes, espaciais entre si ocasionando disputas por espaço, terreno e localização entre as faculdades, um fenômeno já assinalado por Derrida (1999).

Será que poderemos afirmar que estamos próximos do conceito de "complexo universitário" sugerido por Castelo Branco (2012) ou da entropia do sistema físico-espacial e organizacional adotado das IFES?

As condições atuais levam necessariamente à retomada do processo de planejamento territorial das universidades em outras bases. A começar pelo reestabelecimento de um diálogo entre o governo federal e as IFES e, destas, com suas unidades acadêmicas com base nos seus planos pedagógicos previstos na Lei no. 9.394 de 12/12/1996, lei Darcy Ribeiro.

Entretanto, as associações de docentes, discentes, técnico-administrativos e de ex-alunos e aposentados além daquelas provenientes da sociedade civil (redes sociais e ONGs) se mostram interessados na discussão da universidade pública. E por que não considerá-las como participantes desse esforço?

Há outras questões a serem consideradas, a saber:

(a) a inclusão de procedimentos atuais na avaliação dos planos diretores do território universitário a exemplo das audiências públicas (processo participativo previsto por lei federal) e de projetos (arquitetura, urbanismo, paisagismo e mobiliário, entre outros) incluindo a Avaliação Pós-construção (APC) e Avaliação Pós-ocupação (APO);

(b) o resgate de temas que foram esquecidos naquela transição de paradigmas de planejamento, a exemplo, do ciclo básico rediscutido por AlmeidaFilho (2007), das relações campus-cidade, tema recentemente colocado em debate na UFMG;

(c) a inserção do espaço físico como uma variável importante no sistema de planejamento institucional em curso nas IFES; e, (d) a introdução de novas práticas como as do planejamento estratégico amparado, por um lado, no processo participativo e, por outro lado, em informações advindas do conhecimento da universidade e, também, de estudos empíricos acerca do uso de seus espaços.

\section{Referências}

ALENCAR, F. H. A Universidade de Brasília Projeto Nacional da Intelectualidade Brasileira. In: A Universidade Necessária. Darcy Ribeiro. Rio de Janeiro: Paz e Terra, 1978. Apêndice (pp. 271-296).

ALMEIDA, J. G. Humanismo Sacrificado? In: Jornal da Ciência. Ano II no 11. Brasília: 1988 (p. 7). Campus do Milagre: contribuição à análise das propostas arquitetônicas dos campi universitários brasileiros, implantados na década de 1970, tendo em vista a relação entre a autonomia da instituição e a organização espacial. Dissertação de Mestrado em Arquitetura e Urbanismo. Brasília: Universidade de Brasília, 1983.

ALMEIDA-FILHO, N. Universidade Nova: textos críticos e esperançosos. Brasília: Editora da Universidade de Brasília; Salvador: Editora da Universidade Federal da Bahia, 2007.

ATCON, P. R. Manual sobre o Planejamento Integral do Campus Universitário. Santa Catarina: Conselho de Reitores das Universidades Federais CRUB, 1970.

Administração Integral Universitária: uma teoria unificada da estruturação $e$ administração universitárias. Rio de Janeiro: Ministério da Educação/PREMESU (ex CEPES), 1974.

BOSI, A. Ideologia e Contraideologia: temas e variações. São Paulo: Companhia das Letras, 2010.

CASTELO BRANCO, A. A Arquitetura do Sistema Básico. In: Territórios da Universidade: permanências e transformações. Carlos Alberto Maciel e Maria Lúcia Malard (organizadores). Belo Horizonte: Editora da Universidade Federal de Minas Gerais, 2012.

DERRIDA, J. O Olho da Universidade. (Intr. M. 
Peterson; Trad. R. I. Canko e I. A. Neis) São Paulo: Estação Liberdade, 1999.

FÁVERO, M. L. A. Universidade do Brasil: das origens à construção. Rio de Janeiro: Editora da UFRJ/INEP, 2000 v.01.

- Da Universidade "Modernizada" à

Universidade Disciplinada: Atcon e Meira Mattos. São Paulo: Cortez: Autores Associados, 1991.

FUNDAÇÃO UNIVERSIDADE DE BRASÍLIA FUB. Plano Orientador da Universidade de Brasília. Brasília: Editora da Universidade de Brasília, 1962.

KONDER, L. A Questão da Ideologia. São Paulo: Companhia das Letras, 2002.

MACIEL, Carlos Alberto Batista. "O sistema básico da UFMG e seus precedentes: infraestrutura, crescimento, superação da função e construção da paisagem." Brasília: DOCOMOMO, 2011. Disponível em: http://www.docomomo.org.br/seminario\%209\%20 pdfs/110_M25_RM-OSistemaBasicoDAUFMGART_carlos_maciel.pdf. Acessado em 9/6/2013.

MALARD, M. L. A Lógica das Arquiteturas do Campus. In: Territórios da Universidade: permanências e transformações. Carlos Alberto Maciel e Maria Lúcia Malard (organizadores). Belo Horizonte: Editora da Universidade Federal de Minas Gerais, 2012.

MEC/DAU/PREMESU. Relatório de Atividades do Período 1974/1978: Coordenadoria de Desenvolvimento das Instalações do Ensino Superior. Brasília: MEC, 1979.

RASHDALL, H. The Universities of Europe in the Middle Ages. (Edited by F. M. Powicke, A. B. Emden) Great Britain: Oxford University Press, 1945. v. I, II, III.

RIBEIRO, D. A Universidade Necessária. Rio de Janeiro: Editora Paz e Terra, 1978.

Universidade de Brasília. In: Brasília: Revista Brasileira de Estudos Pedagógicos. V. 36, n. 83, julho-setembro 1961 (pp. 161-230).

A Universidade de Brasília. In: Brasília: Educação e Ciências Sociais. Ano 05, V. 08, n. 15 , setembro 1960 (35-98).
SAAVADRA, V. E. O Plano da Cidade Universitária de Conceptión de Emilio Duhart. Arquitextos 108.02 year 092009 (texto acessado em $1 / 6 / 2013)$

(www.vitruvius.com.br/revistas/read/aequitetos/9.1 08/53).

SALMERON, R. A. A Universidade Interrompida: Brasília 1964-1965. Brasília: Editora da Universidade de Brasília, 1999.

SUCUPIRA, N. O Ciclo Básico: sua natureza e problemas de sua organização. In: Brasil Universitário. Rio de Janeiro: CRUB, Ano XXV, 7879, Junho 1970 (pp. 67-74).

UNIVERSIDADE FEDERAL DE MINAS GERAIS (UFMG). O Território Universitário: proposta de um modelo para um sistema ambiental. Belo Horizonte: UFMG, 1970 (apresentado pelo IAB Nacional como tese no XII Congresso Panamericana de Arquitetura em 1970, San Juan Puerto Rico). 